2018-12-07

\title{
Model vs. experiment to predict crop losses
}

Parmesan, Camille

http://hdl.handle.net/10026.1/13679

10.1126/science.aav4827

Science

American Association for the Advancement of Science (AAAS)

All content in PEARL is protected by copyright law. Author manuscripts are made available in accordance with publisher policies. Please cite only the published version using the details provided on the item record or document. In the absence of an open licence (e.g. Creative Commons), permissions for further reuse of content should be sought from the publisher or author. 


\section{Models vs. experiments to predict crop losses from insects}

In their Report "Increase in crop losses to insect pests in a warming climate" (31 August, p. 916), C. A. Deutsch et al. use expected effects of higher temperatures on insect metabolic rates to predict increasing rates of consumption by pests and increasing pest population densities. These predictions fail to recognize the complexity and idiosyncratic nature of plantinsect relationships. They do not take into account changes in plant defense, which can respond to both warming and enhanced $\mathrm{CO}_{2}\left(\mathrm{eCO}_{2}\right)$ in ways that harm some insects and help others $(1,2)$. Furthermore, Deutsch et al. assume that insects will develop predictably faster in response to winter warming. However, warmer winters actually retard development in species whose springtime awakening requires accumulated winter chilling (vernalization) (3). Finally, Deutsch et al. assume that pest population dynamics are simple functions of developmental rates. We doubt this is realistic in the presence of temperature-sensitive predators and diseases, and in the context of pest control (4).

Deutsch et al. may have oversimplified the problem, but their concern is justified. In an experiment estimating effects of moderate warming on maize in Peru, commercial yield was reduced by more than $90 \%$ (far more than Deutsch et al.'s prediction), a reduction that was, indeed, ascribed mainly to increased herbivory (5). The question tackled by Deutsch et al. is extremely important, but the answers will vary among regions and be specific to each crop-pest interaction. We need experiments that compare yields of target crops in replicated experimental treatments that simulate future conditions of both climate and $\mathrm{eCO}_{2}$ in the presence and absence of pests. These experiments seem not yet to exist (6). When they do, we should be able to generate better-informed predictions, both of changes in crop yield and of the roles that insect pests will play in those changes.

Camille Parmesan,1,2,3 Michael E. Hanley,2 Michael C. Singer1,2

${ }_{1}^{1}$ Theroretical and Experimental Ecology, CNRS/Université Paul Sabatier, 09200 Moulis, France. 2Biological and Marine Sciences, Plymouth University, Drake Circus, Plymouth PL48AA, UK. 3 Geological Sciences, University of Texas, Austin. Austin, TX 78712, USA. *Corresponding author.Email: camille.parmesan@plymouth.ac.uk

\section{REFERENCES}

1.P. Stiling, T. Cornelissen, Glob. Change Biol. 13, 1 (2007)

2.C. Robinet, A. Roques, Integrat. Zool. 5, 132 (2010)

3.S. Stålhandske, K. Gotthard, O. Leimar, J. Anim. Ecol. 86, 718 (2017)

4.V. Seufert, N. Ramankutty, J. A. Foley, Nature 485, 229 (2012).

5.R. Tito, H. L. Vasconcelos, K. J. Feeley, Glob. Change Biol. 24, E592 (2018)

6.C. Lesk, E. Coffel, A. W. D'Amato, K. Dodds, R. Horton, Nat. Clim. Change 7, 713 (2017)

10.1126/science.aav4827 